\title{
Time variability of cyclonic geostrophic circulation in the Mediterranean
}

\author{
J. A. Guijarro, A. Jansà, and J. Campins \\ INM Meteorological Centre, Palma de Mallorca, Spain
}

Received: 31 October 2005 - Revised: 23 December 2005 - Accepted: 28 December 2005 - Published: 24 January 2006

\begin{abstract}
Interannual variability and trends of the surface geostrophic cyclonic circulation and cyclone frequency in Western and Eastern Mediterranean areas are analyzed, based on a cyclone data base derived from the ERA-40 ECWMF reanalysis (within the MEDEX project tasks), spanning from September/1957 to August/2002. In this 45 years, the cyclonic circulation show a significant decrease in the Western Mediterranean, mostly in winter and spring, and an increase in the Eastern, mainly due to the summer and autumn increase in the frequency of thermal lows.
\end{abstract}

\section{Introduction}

Cyclones have been recognized since long as a major meteorological feature influencing weather and climate in the Mediterranean region, often producing severe weather events (floods, strong winds, etc).

Early cyclonic climatologies in this region were subjectively derived from hand made analyses (Radinovic, 1978; Genovés and Jansà, 1989), while later more objective cyclone detection methods have been applied to operational or reanalysis data bases (Alpert et al., 1990; Picornell et al., 2001). Most of the climatologies studied the space-frequency distribution of the cyclones (Trigo et al., 1999; Maheras et al., 2001), while others focused on the relation of cyclone frequencies with the precipitation in some areas (Pinto et al., 1999). Trigo et al. (2000) in particular, related the observed precipitation decrease in the Northern Mediterranean basin with a decline of the intense Mediterranean cyclones, balanced by an apparent increase of the non-intense ones.

MEDEX (Mediterranean Experiment on cyclones that produce high impact weather in the Mediterranean; see the home page at http://medex.inm.uib.es) is an international project, whose First Phase was endorsed as a Research and Development Project within the World Weather Research Pro- gramme of the World Meteorological Organisation. One of the MEDEX project results has been the creation of a cyclone data base derived from the ERA-40 ECWMF reanalysis, with the same methodology used by Picornell et al. (2001) and Campins et al. (2005), spanning from September/1957 to August $/ 2002$, which is available at the project web page. In these 45 years, 81762 cyclone centres have been detected at sea level, ranging from meso to synoptic scales.

As a measure of cyclone strength, the geostrophic circulation $(C)$ has been chosen in this work, defined as $C=\int_{A} \int \zeta_{g} d A$ and measured in $\mathrm{m}^{2} \mathrm{~s}^{-1}$, where $\zeta_{g}$ is the geostrophic vorticity and $A$ the cyclone domain (Holton, 1972). Therefore, interannual variability and trends of the cyclonic circulation compiled in the cyclone data base have been analyzed for Western and Eastern Mediterranean areas, and further analysis have also been performed focusing on smaller areas with enhanced cyclogenetic activity: Genoa Gulf and Cyprus area, that bear the highest frequencies of detected cyclones, and the Palos-Algerian sea, with a much lower frequency, but with great importance for the climate of the Spanish Mediterranean.

\section{Methodology}

Dates, coordinates of the cyclonic centers and relative geostrophic circulation values were compiled for the whole Mediterranean area, but the time variability was studied focusing in two big areas (Western and Eastern Mediterranean) and three smaller ones (Cyprus, Genoa-Gulf and Palos-Algeria, see Fig. 1). Cyprus and Genoa-Gulf are the areas with higher frequency of cyclonic locations (e.g. Maheras et al., 2001), while the Palos-Algeria area was selected for its role in the climatic features of the Spanish Mediterranean. Statistical analysis and plots were made with the $R$ package, except for Fig. 1, made with the GRASS GIS. 


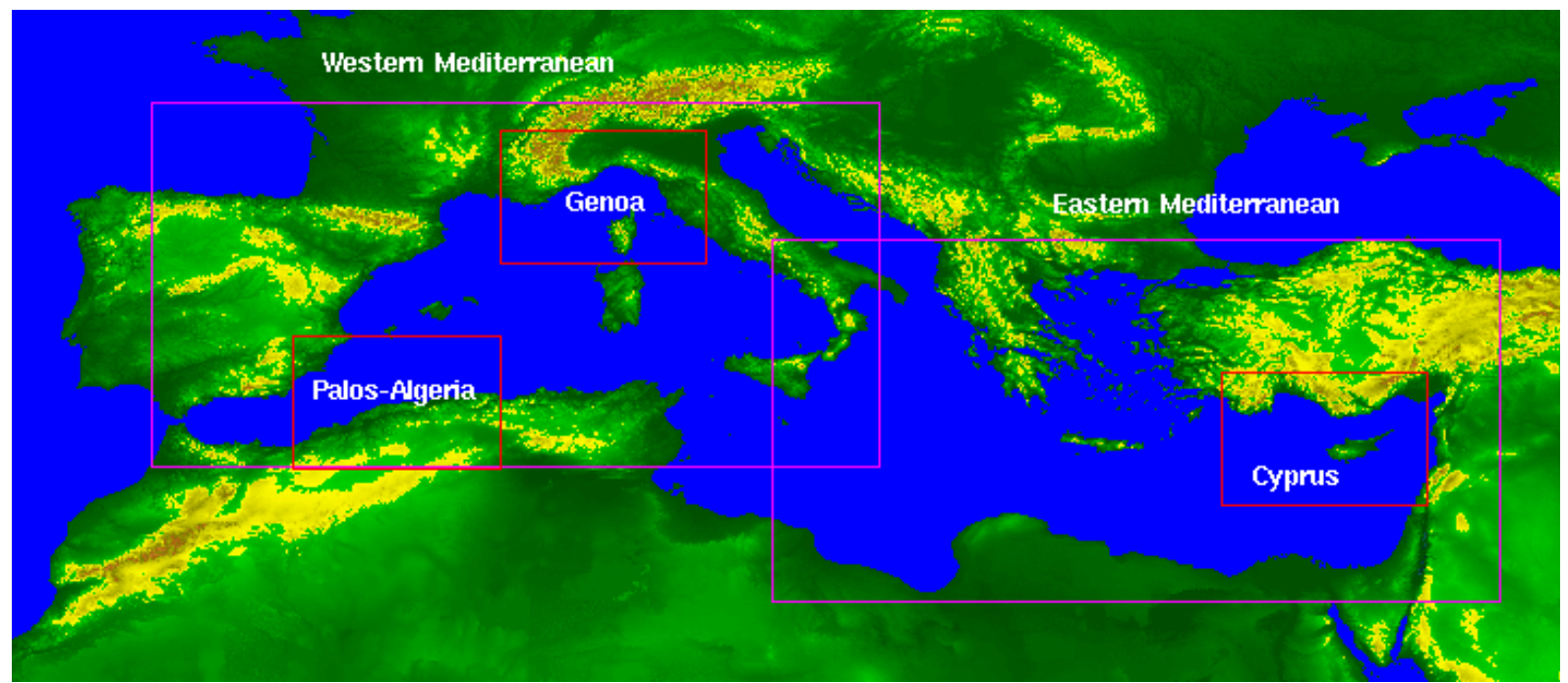

Fig. 1. Geographic framework and location of the studied areas.

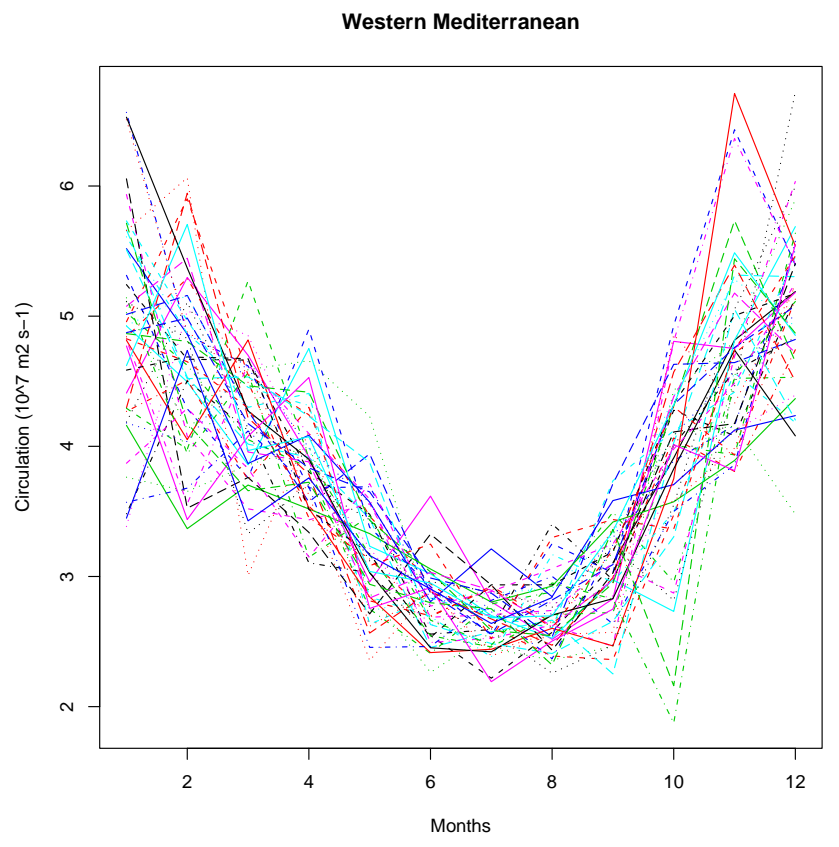

Fig. 2. Monthly averages of cyclonic circulation in the Western Mediterranean (line plots for every year).

\section{Time variability of the cyclonic circulation}

Monthly averages of single cyclone circulation values are plotted in Figs. 2 and 3 for the two major areas, showing a similar pattern, characterized by low values from May to September, and high values (and variability) in the winter months.

Figure 4 show monthly averages for the five studied areas, not in a per cyclone basis, but accounting for the overall monthly circulation values (contributed by all cyclones that have occurred in a region in every month). Eastern Mediter-

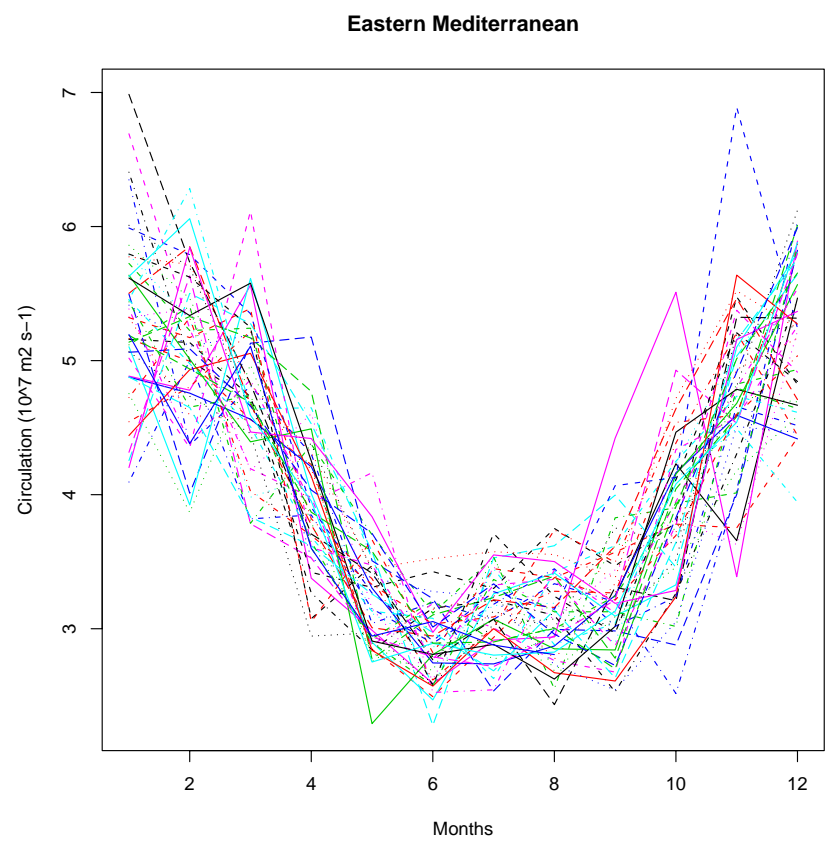

Fig. 3. Monthly averages of cyclonic circulation in the Eastern Mediterranean (line plots for every year).

ranean display the maximum values in winter and March, the rest of them being overcome by the Western circulation figures, with the exception of July, due to the outstanding maximum of the Cyprus area. Palos-Argelia appears as the less active zone in terms of cyclonic circulation.

The trend analysis of the monthly averages of the circulation yields the most significant results in the Eastern areas for the summer months, showing an increase of the cyclonicity (Table 1). In the Western areas only a few months bear significant trends, but all of them are negative, and appear in a rather sparse distribution along the annual cycle. Seasonal 


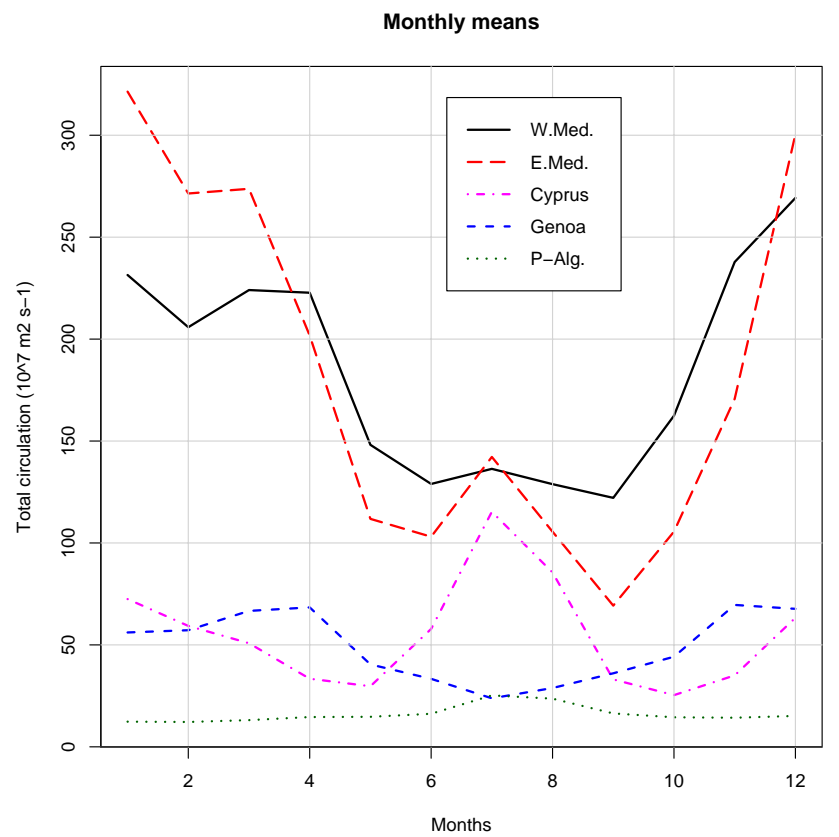

Fig. 4. Overall monthly averages of cyclonic circulation in the five studied areas.

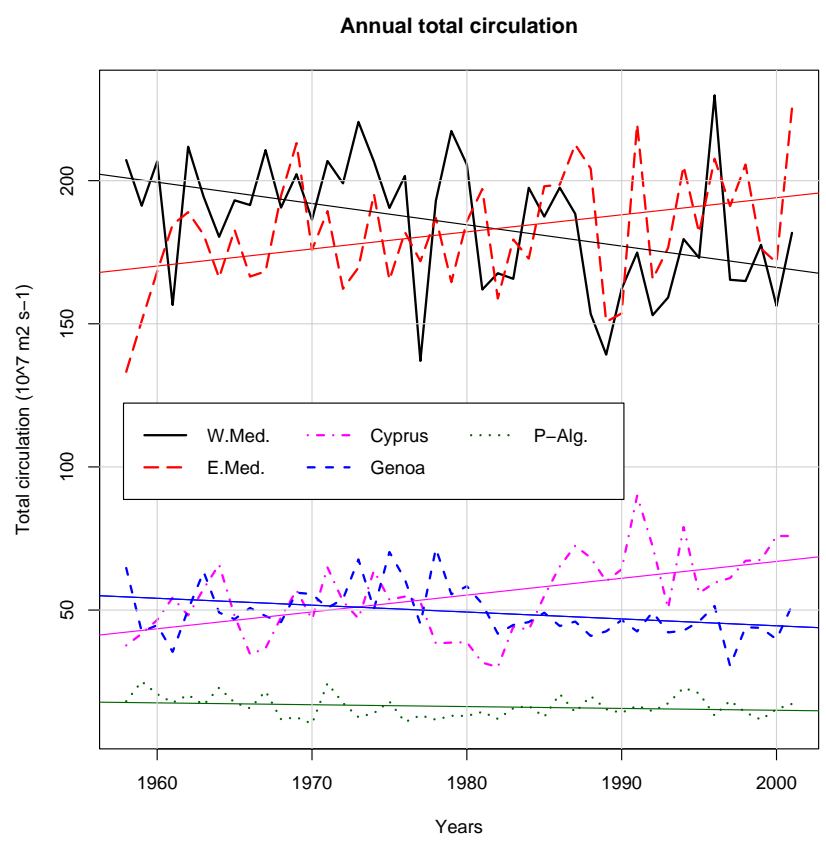

Fig. 5. Annual totals of cyclonic circulation and their trends, in the five studied areas.

significant trends in the East are also positive and confined to summer and autumn, while all seasons bear some negative trends in any of the Western areas. The resulting annual trends are all significant, positive in the East and negative in the West, as shown in Fig. 5.
Table 1. Cyclonic circulation trends $\left(10^{7} \mathrm{~m}^{2} \mathrm{~s}^{-1}\right.$ year $\left.^{-1}\right)$ in the five studied areas. Significant levels marked with: ***(0.001), **(0.01), $*(0.05)$ and $\cdot(0.1)$; only the sign is shown otherwise.

\begin{tabular}{lccccc}
\hline Months & West.M. & East.M. & Cyprus & Genoa & P.Alg. \\
\hline 1 & - & - & - & $-0.99^{*}$ & - \\
2 & - & + & + & - & + \\
3 & -1.95 & - & - & - & - \\
4 & + & - & - & - & - \\
5 & -1.27 & $1.11^{*}$ & $0.68^{*}$ & - & - \\
6 & + & $0.96^{*}$ & $1.36^{* *}$ & + & -0.36 \\
7 & - & $2.22 * * *$ & $2.35^{* * *}$ & $-0.36 *$ & - \\
8 & $-0.96 *$ & $1.68^{* * *}$ & $1.70^{* * *}$ & - & - \\
9 & + & $0.69 *$ & $0.62^{*}$ & + & + \\
10 & - & + & + & + & - \\
11 & - & $2.83^{* * *}$ & $0.70^{*}$ & - & - \\
12 & $-2.22^{*}$ & + & + & - & - \\
\hline Spring & $-3.12^{*}$ & - & - & - & - \\
Summer & - & $4.86^{* * *}$ & $5.41^{* * *}$ & -0.53. & - \\
Autumn & + & $3.85^{* * *}$ & $1.62^{* *}$ & - & $-0.60 *$ \\
Winter & $-4.79 *$ & - & + & $-2.04 * *$ & - \\
\hline Year & $-8.93^{* *}$ & $7.16^{*}$ & $7.71^{* * * *}$ & $-3.30^{*}$ & -2.55 \\
\hline
\end{tabular}

Table 2. Relative seasonal and annual cyclone frequency trends (in $\%$ per 10 years) in the five studied areas. (All cyclones, moderate and strong, and strong only. Significant levels as in Table 1).

\begin{tabular}{ccccccc}
\hline & Cir. & West.M. & East.M. & Cyprus & Genoa & P.Alg. \\
\hline \multirow{4}{*}{ Spr. } & $>0$ & - & + & + & - & + \\
& $\geq 4$ & $-7.8^{* *}$ & -4.9 & - & - & - \\
& $\geq 7$ & - & + & + & - & - \\
\multirow{4}{*}{ Sum. } & $>0$ & - & $14.5^{* * *}$ & $22.0^{* * *}$ & $-8.2^{*}$ & - \\
& $\geq 4$ & + & + & + & + & - \\
& $\geq 7$ & - & NIL & NIL & + & NIL \\
Aut. & $>0$ & - & $10.8^{* * *}$ & $22.2^{* * *}$ & + & - \\
& $\geq 4$ & + & $11.6^{* *}$ & $18.4^{*}$ & - & - \\
& $\geq 7$ & - & 19.2. & + & - & + \\
Win. & $>0$ & $-5.6^{*}$ & - & + & $-7.5^{*}$ & - \\
& $\geq 4$ & $-9.2^{* *}$ & - & + & $-15.1^{* * *}$ & - \\
& $\geq 7$ & -11.0 & - & + & $-18.9^{*}$ & $-50.3^{*}$ \\
Year & $>0$ & $-3.0^{* *}$ & $4.8^{* * *}$ & $14.7^{* * *}$ & $-3.7^{*}$ & - \\
& $\geq 4$ & $-5.4^{* *}$ & - & + & $-7.6^{* *}$ & -12.2 \\
& $\geq 7$ & $-10.0^{*}$ & + & + & $-17.9^{*}$ & - \\
\hline
\end{tabular}

\section{Frequency of cyclonic center occurrence}

Monthly frequencies of detected cyclones have also been computed in the areas under study, classifying them in three categories: 1) all cyclones; 2) moderate and strong cyclones (those with circulation $C \geq 4 \cdot 10^{7} \mathrm{~m}^{2} \mathrm{~s}^{-1}$ ); and 3) strong cyclones $\left(C \geq 7 \cdot 10^{7} \mathrm{~m}^{2} \mathrm{~s}^{-1}\right)$.

The monthly frequencies of all cyclones show different patterns in the annual cycle (Fig. 6), with summer maximums in the Cyprus and the Palos-Algeria areas, and irregular, multi-modal distributions in the other zones. This must 


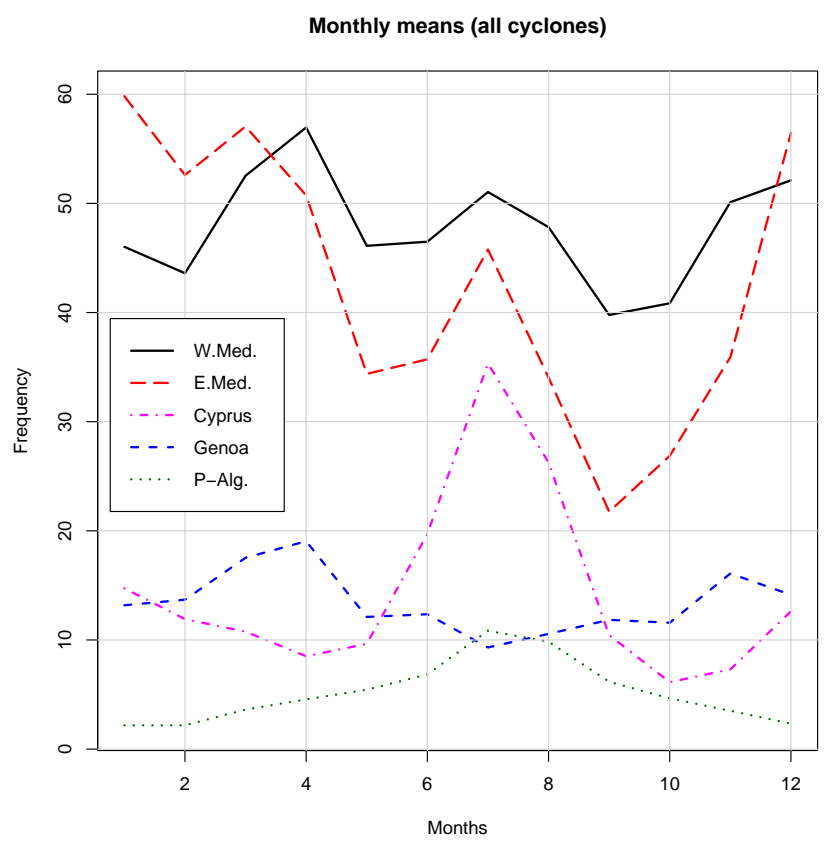

Fig. 6. Monthly frequencies of all detected cyclones.

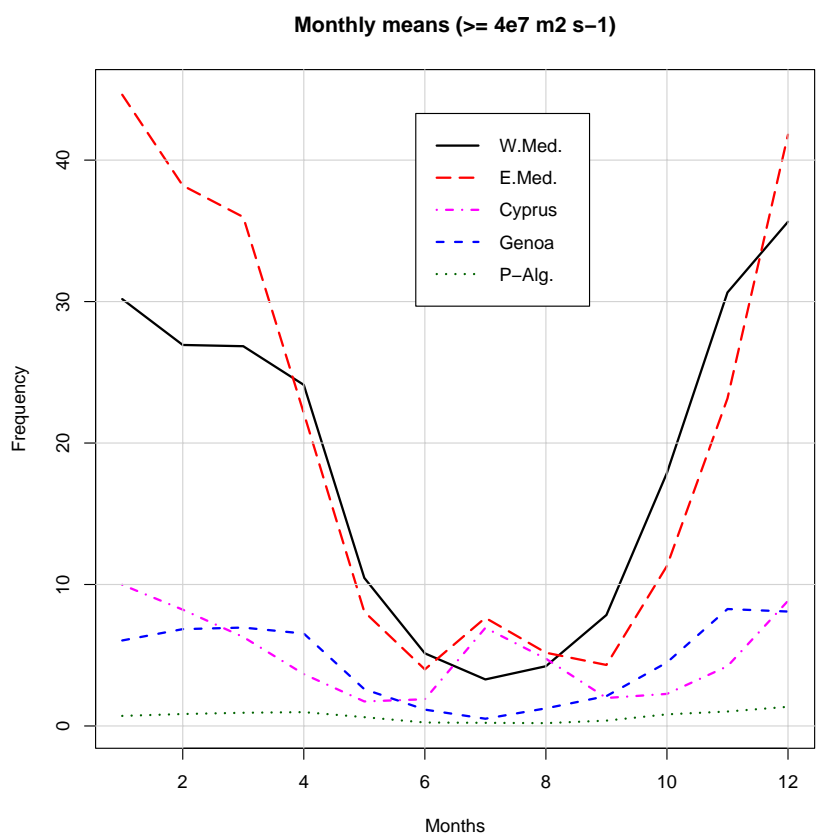

Fig. 7. Monthly frequencies of moderate and strong cyclones.

be the result of the thermal lows contributions, since the moderate and strong cyclone frequencies show the higher values in the winter and early spring months (Fig. 7), though the still prominent Cyprus July maximum is noticeable in the Eastern Mediterranean frequencies. This summer maximum disappears completely in the otherwise similar pattern of the monthly distribution of strong cyclones (not shown).

Trends of the seasonal cyclone frequencies show an opposite behaviour in Western and Eastern Mediterranean (in

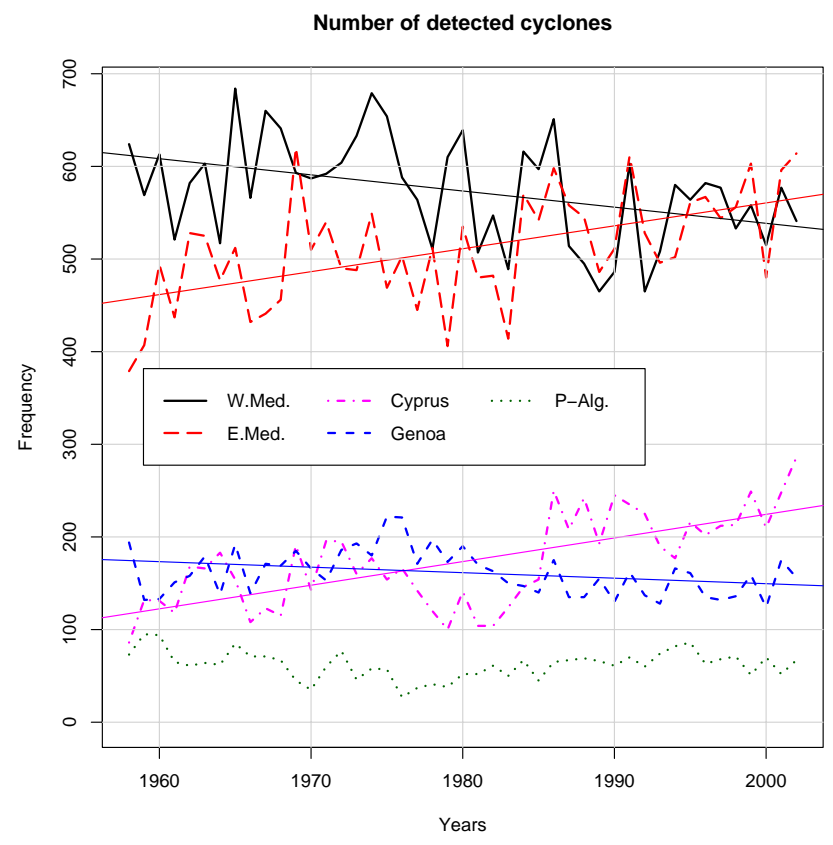

Fig. 8. Time series of annual frequency of detected cyclones in the five areas.

accordance with the circulation trends referred in the previous section): While negative trends in all cyclone categories are significant in winter in the whole West and in the Genoa Gulf (Table 2), positive trends appear in autumn in the East and the Cyprus area, plus in summer with respect to all cyclones (moderate and strong cyclones are too scarce to derive conclusions in this season). Negative annual trends become significant in the West and Genoa for all categories, while in the East only the weak (thermal?) cyclones appear to contribute to the positive annual trends.

Figures 8 and 9 show the temporal evolution of the frequencies of all and moderate/strong cyclones in the five studied areas. Significant trends are plotted as well.

\section{Discussion and conclusions}

The analysis of the cyclones detected from the ERA-40 ECWMF reanalysis show that the cyclonic circulation in the Mediterranean is higher in winter and lower in summer, though summer thermal lows seem the major component in the Cyprus area. The computed trends show a clear increase of the circulation in the Eastern Mediterranean, mainly due to the summer and autumn trends, and a decrease in the Western, generated in winter and spring.

Total cyclone frequencies present varied monthly distributions, but when weak cyclones are removed, the annual cycle is similar to that of the circulation. Frequency trends are negative in the West, mainly in winter, while significant positive trends appear in autumn and summer in the Eastern Mediterranean. 


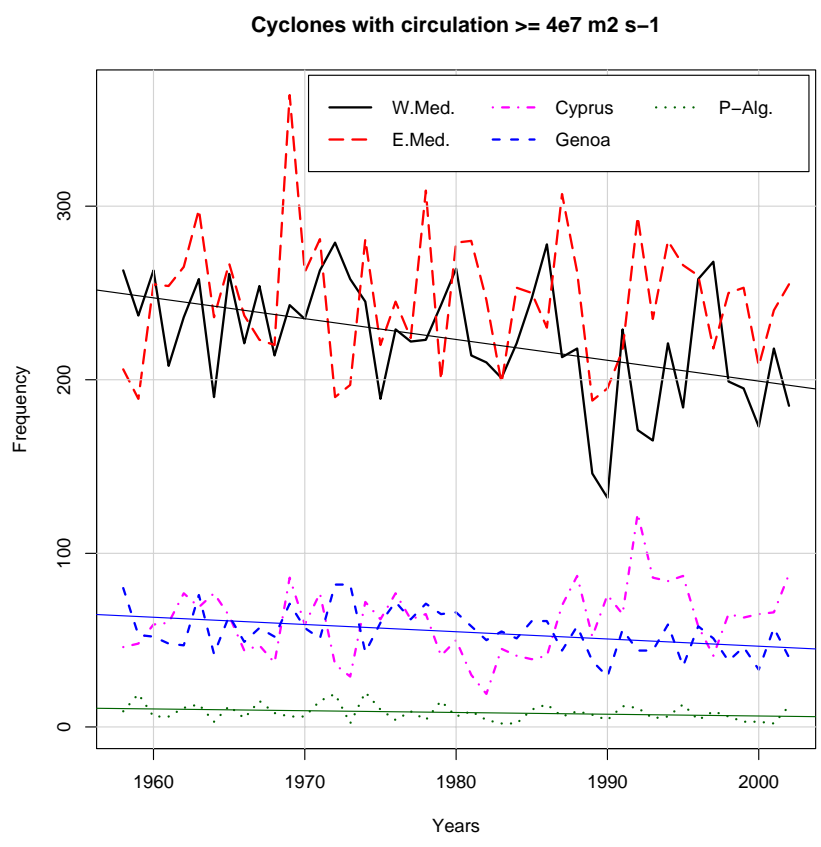

Fig. 9. Time series of annual frequency of moderate and strong cyclones in the five areas.

These trends reflect the general tendencies, but most of these series show a rather irregular behavior, and therefore different trends may arise when decomposing the series in sub-periods. In this respect, many of the cyclone frequency series present a shift in or around 1984 (most noticeable in the Cyprus series) that would make trends non significant when computed after that year.

One of the more relevant aspects of changes in cyclone activity may be a corresponding change in precipitation levels, for its high impact on regional hydric balances and water availability. Connections of precipitation in Mediterranean areas with general circulation patterns (NAO in particular) have been studied by many authors, with varied results. In general, less significance is achieved relating NAO to small scale precipitation levels (Guijarro, 1999) than with broad scale regional precipitation patterns, as those obtained after performing Principal Component Analysis or other similar multivariate tools that reduce variability and filter noise, as found e.g. by Bartzokas et al. (2003) or Quadrelli et al. (2001). The latter refers an observed trend to lower winter precipitation in the Emilia-Romagna Italian region that is in accordance with the observed decreasing winter frequency of Genoa cyclones showed in Table 2.

Our computed annual totals of geostrophic cyclonic circulation are weakly correlated with annual averages of monthly NAO index (obtained from the NOAA Climate Prediction Center), since only the correlation of the Western Mediterranean circulation $(r=-0.25)$ appears statistically significant, though only at the $\alpha=0.10$ level. No significant correlation is obtained with the cyclone frequencies of all intensities, due to the presence of a great number of weak, mesoscale cyclones, but the correlation with moderate and strong cy- clone frequencies becomes significant at $\alpha=0.05$ (though not at $\alpha=0.01$ ) for both Western and Eastern Mediterranean big areas ( $r=-0.31$ and -0.35 respectively), showing some influence of the North Atlantic Oscillation pattern in preventing strong cyclogenesis in the whole sea.

Acknowledgements. We want to thank the ECMWF for developing the ERA-40 reanalysis, and the Mediterranean Studies Section of the Centro Meteorológico en Illes Balears for building the cyclone data base. We are also grateful for the referee's comments, that have helped in improving the original manuscript.

Edited by: V. Kotroni and K. Lagouvardos

Reviewed by: anonymous referee

\section{References}

Alpert, P., Neeman, B. U., and Shay-El, Y.: Climatological Analysis of Mediterranean cyclones using ECMWF data, Tellus, 42A, 6577, 1990.

Bartzokas, A., Lolis, C. J., and Metaxas, D. A.: The 850 hpa relative vorticity centres of action for winter precipitation in the greek area, Int. J. Climatol., 23, 813-828, 2003.

Campins, J., Jansà, A., and Genovés, A.: Three-dimensional structure of Western Mediterranean cyclones, Int. J. Climatol., accepted, 2005.

Genovés, A. and Jansà, A.: Statistical approach to mesoscale nonalpine West Mediterranean cyclogenesis, WMO/TD No. 298, 77-85, 1989.

Guijarro, J. A.: Teleconexiones climáticas y precipitación en la España Mediterránea, in: La Climatología española en los albores del siglo XXI, edited by: Raso, J. M. and Martín-Vide, J., Asociación Española de Climatología, A-1, 243-251, 1999.

Holton, J. R.: An Introduction to Dynamic Meteorology, Academic Press, New York, 1972.

Maheras, P., Flocas, H., Patrikas, I., and Anagnostopoulou, C.: A 40 year objective climatology of surface cyclones in the Mediterranean region: Spatial and temporal distribution, Int. J. Climatol., 21, 109-130, 2001.

Picornell, M.A., Jansà, A., Genovés, A. and Campins, J.: Automated database of mesocyclones from HIRLAM(INM) $-0.5^{\circ}$ analyses in the Western Mediterranean, Int. J. Climatol., 21, 335354, 2001.

Pinto, J. G., Ulbrich, U., and Speth, P.: The variability of cyclonic activity in the Mediterranean Area in the last 40 years and its impact on precipitation. Proceedings of the 1st EGS Plinius Conference, Maratea, Italy, October 1999, 29-40, 1999.

Quadrelli, R., Pavan, V., and Molteni, F.: Wintertime variability of Mediterranean precipitation and its links with large-scale circulation anomalies, Clim. Dyn., 17, 457-466, 2001.

Radinovic, D.: Numerical model requirements for the Mediterranean area, Riv. Met. Aer., 38, 191-205, 1978.

Trigo, I. F., Davies, T. D., and Bigg, G. R.: Objective climatology of cyclones in the Mediterranean region, J. Clim., 12, 1685-1696, 1999.

Trigo, I. F., Davies, T. D., and Bigg, G. R.: Decline in Mediterranean rainfall caused by weakening of Mediterranean cyclones, Geophys. Res. Lett., 27, 2913-2916, 2000. 